\title{
On the Phenomenology of Writing
}

\section{Don McEachern}

University of Alberta

\section{Poem}

Language is the thing we most take for granted, the thing we think least about. Yet, it is the means by which we carry meaning and the method by which we understand. Unfortunately, educators often view language simply as a tool, an instrument for the transfer of thought from one mind to another. Thus, the student is viewed as a "consumer" of the common currency of his native language. In such a metaphor, speech is a symbol of thought while writing is a symbol of speech. This makes writing a symbol of a symbol, just as a check is a symbol of money, which is a symbol of purchasing power. While this metaphor captures the general approach of modern educators, it tells us little about the immediate reality involved in the lifeworld of a student on a Monday morning.

In classrooms throughout the world, students are given paper and pen and writing assignments, but what exactly is being asked of these students? What demands does writing make on the writer? These are questions which lend themselves to phenomenological description which attempts to describe ordinary experiences as they present themselves to consciousness. The description that follows is "personal" in nature, yet it is phenomenological in that it is a direct exploration of what Langeveld calls "personal sense-making" as experienced in the writing act.

My description rests most heavily on my own experience, yet I include the thoughts of poets famous and unknown. These poets are not part of an appeal to eminent authority, rather they represent "poet" in the original Greek meaning of "maker"- the "makers" of personal sense, the "makers" of meaning.

If students are to be viewed as "makers," teachers must come to understand this process. Teachers become only "markers" when they can read only words and not understand minds and intentions. While there is a need for a phenomenological view of writing within the classroom, perhaps the first step is for teachers of composition to explore their own experiences and, thus, renew their understanding of the significance of the writing act.

One final word is required. The following paper makes use of a "mirror" metaphor, and metaphors often carry with them an uncomfortable sense of the "unreal." Perhaps my intentions can best be given 
substance in the words of François Jacob (1982), a professor of the College de France and the Institut Pasteur, and the winner of the Nobel Prize in Medicine:

It is difficult to decide at what stage of evolution it is possible to detect a beginning of self-awareness. One of the clues might be found in the capacity to recognize oneself in a mirror, a capacity which is considered to occur only at a certain level of complexity in the evolution of primates. Combined with the capacity for imagery, through which one recombines pieces of "reality" to re-create a representation of possible worlds in one's imagination, self-awareness provides a way of assessing the existence of a past that occurred before one's own life. It also enables one to imagine a time to come, to invent a future that contains one's death and even a time after one's death. It allows a departure from the actual and the creation of a possible. (p. 59)

\section{"Being" Edged-Out: Writing on Mirrors with Reflections}

My thought ended in nothing.

It was like a line

That all runs out.

Would I ever, I wondered

Have firm ground to stand on?

Magic words I mumbled all the way.

Kingmerut-Inuit poem

"What are you thinking?" she asked.

"Who, me?" he replied.

Canadian dialogue

While we speak of pre-literate and literate societies, we find it impossible to visualize a world without language where everyone is a foreigner to everyone else, where there is no communication and no interpretation, where even gestures fail because they are based on ideas that are couched in language. The purpose of this paper is to describe the "magic mumblings" of one person ... me. What follows is not meant to be metaphysical or metapsychological in nature, but merely one man's description of his search for the common ground of human experience found within language. Such a search, however, is inextricably linked to a quest for meaning, a need to discern forms and patterns, a paradoxical hope for clarity in mystery. What I propose is the description of a process, a textual tour through an inner experience involving the interweaving actions of language, thought, and the awareness of being.

I should like to begin by putting a time and place to my description by isolating certain artificial "realities." Perhaps a gesture of identification will help to situate the process in which my reality and my language subsist. 
I am sitting in the silence of my country home during that time of year held together by snow and cold and impatiently awaiting the arrival of warmer soil. On my desk is my "Course Diary," my frustrating fumblings in coming to "terms" with speaking phenomenologically for Max van Manen's course entitled "Pedagogical Theorizing." As well, my desk is covered with three drafts of my own work which indicate a shift in topic from a description of writing to a description of writing a journal. What I am writing now, what you are reading now, represents yet another shift, but it is my intention fulfilled.

I seek after words, the primal, inner journey into meaning:

Perhaps-well

It may not matter!

Perhaps-well

My tongue merely joins words

Into a little song.

A little mouth,

Curling downward at the corners,

Like a bent twig

For a kayak rib.

Netsit-Inuit poem

It is a voyage that calls attention to the paper, the print, and the poem. Further, it is demonstrative of the hidden requirement that writing invokes that writers "edge" themselves out.

Conrad once bitterly complained that writing in English was "like throwing mud at a wall," an apt analogy considering the similar functions of walls and paper. Both are structures serving to enclose, divide, protect. From its origin, writing on paper has been a way of protecting facts, events, or creations from the transformation of time and space. But what is enclosed on paper? What is divided?

In his phenomenological description of writing, Loren Barritt (1981) examines the statement, "When I write, I sit down, pick up my pen, and begin to write words on paper." But the inner voyage begins when our gaze is captured by the hypnotic glare of a blank, white sheet of paper. It is impossible to recognize the world beyond those two-dimensional edges, just as it is impossible to focus on a point of whiteness held within. We are left only with edges-borders hemming in, margins marking beginning or end, opening or close. Awareness of edge is the beginning of the act of naming, the performance of description, the process of interpretation.

"I am the great god," Ra said, "who came into being by himself, I created my own name." Common amongst our mythologies is the god who creates things by creating their names - and the edged paper before us calls forth an act of naming in just this way: not a labeling 
of the pre-existent but an utterance that itself summons new experience into being. The new experience summoned into being is the edging of form on content, the awareness of the edges of being itself. Thus, we stare at the blank page as we might a misty mirror waiting to see ourselves take shape:

Do we know what silence is, my friends, or not?

This life that faces both ways has marked the human face from within.

Rainer Maria Rilke--Sonnets to Orpheus

The white blinding silence of the sheet before us demands that we give definition to the sounds of our confusion of thoughts, images, memories, interior dialogues, regrets, wishes, and resolves. Two-dimensional paper reminds us that writing is artifice, not simply a way of saying something to someone. The spoken language, looping back and forth between speakers, offering opportunities for groping, retreating, and even hiding, allowing for the accent of hands and faces, of pitch and pauses, permits shadowy margins, indefinite edges. How harsh seems the world of written language, the line that must move haltingly across the page, exposing ignorance, revealing being, and then passing into the hands of a stranger.

The blank page signals the need for different coordinations from those of speech. Its edges inhibit us. Like the centipede who could no longer walk after trying to analyze how he did it, we often conclude that we cannot write on the page, simply because we are uncertain about our own edges, ourselves. Why are we "uncertain"? Perhaps it is because the empty sheet demands that part of us, our thoughts, develops its own autonomous identity. Writing begins, in a sense, where speech leaves off-the shapeless thought that is generated in speech must be given explicit and independent form.

Just as Conrad's "wall" acts as paper, so his "mud" fits the printed word on the page. Words swallow meaning like speech swallows silence. Words force us to separate what is meant from what is said, and what is said from what is implied, and what is implied from what is revealed. At the same time, words cannot be trusted. Our words have lied, and although on occasion a revelation may be beaten from them, they admit to no standard; they have soiled consciousness too continuously. Words give edges to objects, to things, and these edges take on their own special meaning.

Words, like mirrors, bring us face to face with ourselves. "How do I know what I think," wrote W. H. Auden, "until I see what I say?" Thus, we must become conscious of what we want to say; otherwise, we cannot judge how close we have come to saying it. Words require that we make judgments about what is essential. The poet Patrick Lane offers modern man's linkage to the word, the naming of Ra: 
In the still centre of the still word

There is no stillness. I am the word.

Patrick Lane-Temenos

When we seek that which is essential in a word, any word, we find only paradox. What we want is whatever our words represent-the things, not the thoughts, the things, not the sounds, the things, not the printed letters-and then only those things "things" designate. The paradox rests in the situation that language has been inventing itself for centuries. Thus, every word is a completed presence in the world, a recognizable being apart from any object. Like a frightened turtle, a word moves into itself so that beyond the edges of its own special meaning we discern yet other edges, other meaning.

First faint scream,

Out of life's unfathomable dawn,

Far off, so far, like a madness, under the horizon's dawning rim,

Far, far off, far scream.

D. H. Lawrence-Tortoise Shout

The act that calls forth expression, utterance, naming-be it "turtle"/"turtle scream," "word"/"meaning," or "signifier"/"signified"-is a confrontation with the contradictions and paradoxes of reality versus abstraction. The complexity found in the word is deceptively present in S. I. Hayakawa's simple rule: COW ${ }^{1}$ IS NOT $\mathrm{COW}^{2}, \mathrm{COW}^{2}$ IS NOT $\mathrm{COW}^{3}, \ldots$ :

The word "cow" gives us the intensional meanings, informative and affective; it calls up in our minds the features that this "cow" has in common with other "cows." The index number, however, reminds us that this one is different; it reminds us that "cow" does not tell us "all about" the event; it reminds us of the characteristics left out in the process of abstracting; it prevents us from equating the word with the thing.

Thus, a word is not a simple naming of what "is," but a recognition of commonality and difference that can never be joined in synthesis. When we focus on "the event," we see nothing but differences. Yet, when we focus on differences, we see their subordination to commonality. Each perspective shows the error of the other in an irresolvable dialectic. "What are man's truths after all? They are man's irrefutable errors." "Truth is the kind of error without which a certain species of living being could not live." These statements of Nietzsche, dealing with the problematizing of the opposition between "truths" and "errors," indicate the manner in which, when dealing with "commonality" and "difference," neither description is more accurate than the other.

Sitting at the desk, bending over the silent sheet, seeking the root of expression, we find an awareness of the paradoxical structure of a 
conscious existence, of an existence which becomes "thing" while hovering over "thing." But where does this "awareness" direct us in our inner journey into meaning? Within phenomenology, two polarities of interpretation are offered as possibilities in the works of Martin Heidegger and Jacques Derrida. Since "metaphors speak of what remains absent" ( Harries, 1978), perhaps metaphor will give the clearest understanding of these two interpretations.

Imagine that the two-dimensional, white sheet of paper before you has become white sand, a traditional representation of the passage of time, over which crystal clear water streams, representing the journey through life. Further, imagine that the stream flows from right to left. The mysterious essence that we seek to name and which is lost in the word is always just beyond the edge of our waterscape. Our knowledge of its presence depends on the shadows edged on the sand by its ebbs and eddies. Heidegger's view of interpretation is reconstructionist; that is, he places the essence to the right of the page. His position is retrospective, the narrower, more distinct edges on the right coming closest to "the thing itself." While Heidegger states that "like swimming, only a leap in the river will teach the meaning," his search takes him upstream, against the flow of common meaning, to a source of meaning lost to modern man.

Words must be chosen, and be placed with skill:

You gain your point, if your industrious art

Can make unusual words easy and plain;

But if you write of things abstruse or new,

Some of your own inventing may be used,

So it be seldom and discreetly done:

But he that hopes to have new words allowed,

Must so derive them from the Grecian spring

As they may seem to flow without constraint.

Horace-The Art of Poetry

It would be naive to suggest that Heidegger, or that we, can believe that the "thing itself" can be found in "the Grecian spring." The reconstruction of the word is the method by which we move from a fixed meaning into a full realization. In the word all tradition is simultaneous with any present time: It is not a remnant but a unique coexistence of past and present, the primordial connection of printed word to Paleolithic cave painting-Conrad's "mud on the wall."

Jacques Derrida offers a somewhat different interpretation of the waterscape metaphor. We still see shadows edged on the sand before us, yet there is no motion as the stream moves from right to left, and the ebbs and eddies are not directly linked to "things" just beyond the margin. Derrida turns from the idea that there exists a simple "moment of presence"; that is, the motion of the water is conceivable only if we are aware that every "moment," every present state, is marked with the "traces" of the past and the future. Each moment 
requires reference to moments which are not present. Thus, the meaning of a word is dependent for its identity on differences and relations that can never be present. The indeterminacy of word meaning requires that we constantly deconstruct words to grasp the traces of the "not-now" in the "now."

Derrida tells us that no word, no "thing" that the word gives edges, is "present" in and of itself, referring only to itself. This interweaving of presence and absence, synthesis and referral, difference and "trace," echoes the earlier statements of S. I. Hayakawa, but Derrida (1981) labels the problematical complexity différance.

Différance, then, is a structure and a movement no longer conceivable on the basis of the opposition presence/absence. Differance is the systematic play of differences, of the traces of differences, of the spacing by means of which elements are related to each other. This spacing is the simultaneously active and passive (the $a$ of différance indicates this indecision as concerns activity and passivity, that which cannot be governed by or distributed between the terms of this opposition) production of the intervals without which the "full" terms would not signify, would not function. (p. 27)

In a paper that purports to be "a textual tour through an inner experience," perhaps the appearance of Hayakawa, Heidegger, and Derrida should be brought to question. Yet, if not these men, would not the names Spinoza, Schopenhauer, and Nietzsche, or their equivalents, appear? The journey into paper, print, and poem is a journey into what we believe we are, the genesis of philosophy, philosophy which cannot escape its own words. We begin with the intention of having our "selves," our words, our edges understood, but we end trying to understand. Our attempts to understand the sense of the word bring us face to face with our existence as learning beings seeking to specify our own uniqueness.

The poem is a coming together of paper, print, and "trying to understand." Current critical theory offers a large number of possible semantic distinctions between "the poem" and "the text," but the inner process needs no complex explanation for the interaction of writer, reader, and writing. The poem without a "trying to understand" is mere text, ordered symbols which lack our own voice, our own interpretation, the penetration of our own privacy. Text is notation without definition and connotation, form without differance. Text is the action of not thinking-words function only as reproducing apparatus.

The poem demands a "trying to understand." It does not have a separate existence "out there" on the paper-each word, each sentence is a container of our consciousness: 
Poetry is the subject of the poem,

From this the poem issues and

To this returns. Between the two,

Between issue and return, there is

An absence in reality,

Things as they are. Or so we say.

But are these separate? Is it

An absence for the poem, which acquires

Its true appearances there, sun's green,

Cloud's red, earth feeling, sky that thinks?

From these it takes. Perhaps it gives,

In the universal intercourse.

Wallace Stevens-The Man with the Blue Guitar

This "universal intercourse," the irresolvable dialectic of thing and thought, is what constitutes the poem. Thus, the poem must reflect our human life experience shaped within language. It requires both the "knowing" of definition and the "feeling" of connotation. In the poem, writing becomes an act of revelation, an act of confidence, an assertion of the importance of what has gone on within, an exhibition of thoughts and experience.

But the poem is also "shaped within language" and must come to terms with the writing process itself. We have-or feel that we have-almost an infinite number of ways of saying what we have to say. But with each word written down, the field of choices narrows. The sentences seem to develop themselves and move with predictability in the direction that idiom, syntax, and semantics leave open. If the origin of the sentences is without poem, then they develop as measures, thoughts without meaning, space without experience. When the origin rests in a "trying to understand," then sentences develop as immersions, flooding our space with meaning, accepting the words as our own. The origin determines whether we write things "down" or simply write them "up."

The poet's eye, in a fine frenzy rolling,

Doth glance from heaven to earth, from earth to heaven;

And as imagination bodies forth

The form of things unknown, the poet's pen

Turns them to shapes, and gives to airy nothing

A local habitation and a name.

Shakespeare-A Midsummer Night's Dream

To give edges to "airy" nothings, to see différance, is the subtle, complicated, and relatively unquantifiable root of composition. Yet, the writing process imposes its own edges. The typed letter, the printed word, the well-formed sentence show us the edges of function and familiarity. To give our thoughts edges, explicit and independent form, requires the ability to subordinate some elements of an idea 
and to conjoin other elements of equal weight. The nature of the medium imposes the need to get all the letters in the word, to get the words in the right place, to point up relationships between words and between sentences, and to be aware of the neutral possibilities of words so as to avoid distortions and misunderstandings. We seek the transformation of our understanding through words and, as Gadamer (1975) points out, "the process of understanding moves entirely in the sphere of a meaning mediated by the linguistic tradition."

I am sitting in the silence of my country home during that time of year held together by snow and cold and impatiently awaiting the arrival of warmer soil. On my desk are only these pages that I have written. They are my poem, my understanding of the inner journey called forth in the act of composition. Yet, I know that the poem is incomplete without an audience. You and I, reader and writer, must connect through these words. Will I be "corrected" as text or "read" as poem?

The house was quiet and the world was calm.

The reader became the book; and summer night

Was like the conscious being of the book.

The house was quiet and the world was calm.

The words were spoken as if there was no book,

Except that the reader leaned above the page.

Wallace Stevens-Collected Poems

Distance can turn my words into one-way mirrors, behind which my magic mumblings disturb nobody.

\section{Addendum: Reflections in a Rear-View Mirror}

I have attempted to describe the inner process involved in composition. But what are the pedagogical implications? What do we, as teachers, ask of students when we ask them to write? What are the hidden requirements that writing invokes? Perhaps the following points best summarize my own quest for meaning in language:

1. Beyond its function to record, writing is the means by which we shape ourselves-the instrument by which we seek our edges.

2. What we believe we are is inextricably linked to the expression and definition of our humanity through all writing that affords us an enlarged, external, and common memory.

3. The heuristic function of writing takes us away from the conception of meaning contained within language and guides us toward the indispensable context of situation-the importance of poem over text.

4. Written expression involves hazard: the unknown future called for in composition brings us face to face with our unknown present. 
5. Writing that represents a "trying to understand" is an affirmation of our questioning nature, the primal recognition that we are learning beings.

6. Students taught to write in a certain way because that is the way they should write lose their poem in text-they are reduced from learning beings to mimical beings.

7. Teachers must read sentences as containers of consciousness rather than "correct" them as proper constructions.

8. In order to use writing as an expressive act, the means of shaping private experience and naming situation, students must learn to write their felt thoughts, not what they think is expected of them.

9. When teachers go beyond the mechanical correctness of student writing, they begin to include the situational drama which is unfolding in students' lives-their experiences, their expectations, and their intentions.

10. Students must receive some reflection of their poem back from their teacher or else they will sit back, hiding themselves in text, camouflaging thcir uncertainties, guarding their newly developed identities.

Words come without meanings

Students without instructions

Perhaps it's best,

Lest trees that crash in the forest

Come complete with philosophy.

Don McEachern

\section{References}

Colombo, J. R. (Ed.). (1981). Poems of the Inuit. Toronto: Oberon Press.

Derrida, J. (1978). Of grammatology. Baltimore, MD: The Johns Hopkins University Press.

Derrida, J. (1979). Speech and phenomena. Evanston: Northwestern University Press.

Derrida, J. (1981). Positions. Chicago: The University of Chicago Press.

Gadamer, H. (1975). Truth and method. New York: The Seabury Press.

Harries, K. (1978). Metaphor and transcendence. In S. Sacks (Ed.), On metaphor. Chicago: The University of Chicago Press.

Hayakawa, S. I. (1941). Language in action. New York: Harcourt, Brace \& Co.

Heidegger, M. (1967). What is a thing? South Bend, IN: Regnery/Gateway, Inc.

Heidegger, M. (1968). What is called thinking? New York: Harper Colophon Books.

Jacob, F. (1982). The possible and the actual. New York: Pantheon Books.

Kroll, B. M., \& Vann, R. J. (Eds.). (1981). Exploring speaking-writing relationships: Connections and contrasts. Urbana, IL: NCTE.

Lane, P. (1978). Poems new and selected. Toronto: Oxford University Press. 
Langeveld, M. J. (1984). How does the child experience the world of things?

(See this issue of Phenomenology + Pedagogy.)

Rilke, R. M. (1981). Selected poems of Rainer Maria Rilke. New York: Harper Colophon Books.

Stevens, W. (1964). Collected poems. New York: Knopf. 